\title{
Postseismic relaxation driven by brittle creep: A possible mechanism to reconcile geodetic measurements and the decay rate of aftershocks, application to the Chi-Chi earthquake,
}

\section{Taiwan}

\author{
H. Perfettini ${ }^{1}$ and J.-P. Avouac \\ Geological and Planetary Science Division, California Institute of Technology, Pasadena, California, USA
}

Received 10 March 2003; revised 25 September 2003; accepted 31 October 2003; published 3 February 2004.

[1] We evaluate the effect of coseismic stress changes on the fault slip at midcrustal depth, assuming a velocity-strengthening brittle creep rheology. We show that this model can help reconcile the time evolution of afterslip, as measured from geodesy, with aftershocks decay. We propose an analytical expression for slip of the brittle creeping fault zone (BCFZ) that applies to any dynamic or static stress perturbation, including shear stress and normal stress changes. The model predicts an initial logarithmic increase of slip with time. Postseismic slip rate decays over a characteristic time $t_{r}=\frac{a \sigma}{\dot{\tau}}$ that does not depend on the amplitude of the stress perturbation, and it asymptotically joins the longterm creep imposed by interseismic stress buildup $\dot{\tau}$. Given that the seismicity rate might be considered proportional to the sliding velocity of the BCFZ, the model predicts a decay rate of aftershocks that follows Omori's law, with a mathematical formalism identical to that of Dieterich [1994] although based on a different mechanical rationale. Our model also differs from Dieterich's model in that it requires that aftershock sequences and deep afterslip, as constrained from geodetic measurements, should follow the same temporal evolution. We test this for the 1999 Chi-Chi earthquake, $M_{w}=7.6$ and find that both sets of data are consistent with a model of afterslip due to the response of the BCFZ. The inferred relaxation time $t_{r}=8.5$ years requires a value for $a=\partial \mu / \partial \log (V)$ ( $\mu$ being the coefficient of friction) in the range between $1.310^{-3}$ and $10^{-2}$. INDEX TERMS: 3210 Mathematical Geophysics: Modeling; 3902 Mineral Physics: Creep and deformation; 5120 Physical Properties of Rocks: Plasticity, diffusion, and creep; 8123 Tectonophysics: Dynamics, seismotectonics; 8159 Tectonophysics: Rheology—crust and lithosphere; KEYWORDS: postseismic relaxation, Omori law, Chi-Chi earthquake

Citation: Perfettini, H., and J.-P. Avouac (2004), Postseismic relaxation driven by brittle creep: A possible mechanism to reconcile geodetic measurements and the decay rate of aftershocks, application to the Chi-Chi earthquake, Taiwan, J. Geophys. Res., 109, B02304, doi:10.1029/2003JB002488.

\section{Introduction}

[2] In this paper, we discuss the dynamic response of brittle creep and the potential role of this mechanism to explain some aspects of fault behavior including postseismic slip, aftershocks and triggered seismicity. It is commonly admitted that throughout the upper crust, deformation is accommodated by cataclastic (brittle) processes while ductile deformation, dominated by thermally activated dislocation creep, would prevail in the lower crust. The key point for seismogenesis is that brittle deformation may be either rate weakening, allowing for runaway seismic rupture or rate strengthening, favoring quasi-static stable shear. Both experimental results and theoretical consideration show that rate strengthening is thermally activated and

\footnotetext{
${ }^{1}$ Now at Institut de Recherche pour le Développement/Laboratoire des Mécanismes de Transferts en Géologie, Toulouse, France.

Copyright 2004 by the American Geophysical Union. 0148-0227/04/2003JB002488\$09.00
}

enhanced by the presence of fluids due to physicochemical effects and dilatancy [Blanpied et al., 1991, 1995; Chester, 1995; Marone, 1998; Frye and Marone, 2002]. It follows that rate strengthening may occur at shallow depth on faults cutting through loose sediments [Marone and Scholz, 1988] or at midcrustal depths where temperature gets higher than about $250^{\circ} \mathrm{C}$ but remains too low to activate ductile flow associated with crystal plasticity. Hereinafter we refer to this midcrustal fault portion as the brittle creeping fault zone (BCFZ).

[3] The motivation of the present study lies in our belief that the importance of rate-strengthening brittle creep (hereinafter referred to as "brittle creep") has been somewhat overlooked in seismotectonic studies. This mechanism has not been ignored however. It has been advocated to explain postseismic slip at shallow depth on a ruptured fault [Marone et al., 1991] and has been advocated to explain deep afterslip in few case studies, in particular following the 1999 Izmit earthquake [Hearn et al., 2002]. Also it is explicitly accounted for in conceptual models of the seismic 
cycle based on static fatigue [Main, 2000] or on friction laws [e.g., Tse and Rice, 1986; Lapusta et al., 2000]. Such models, which ignore the viscous response of the crust, predict a postseismic relaxation in the form of afterslip governed by brittle creep. This is in keeping with evidence for afterslip at midcrustal depths observed following many earthquakes [Savage and Svarc, 1997; Burgmann et al., 1997; Pollitz et al., 1998; Segall et al., 2000; Hsu et al., 2002; Melbourne et al., 2002; Owen et al., 2002]. Also the microstructure of fault zones exhumed from midcrustal depths does sometimes bear evidence for postseismic relaxation [Trepmann and Stockhert, 2002]. By contrast, mechanical models of postseismic deformation designed to fit observational data generally ignore the specific response of this fault portion [e.g., Pollitz et al., 2000; Pollitz, 2001; Cohen, 2000; Deng et al., 1999; Zheng et al., 1996; Khazaradze et al., 2002]. Either afterslip is not explicitly modeled, or it is considered to be driven by viscous deformation. Such models can be adjusted to fit postseismic geodetic data quite satisfactorily, but they are quite ineffective at explaining simultaneously the decay rate of aftershocks [e.g., Deng et al., 1999]. The current most popular model of aftershocks sequence does not imply any direct link between postseismic deformation and aftershocks [Dieterich, 1994]. According to Dieterich's model, aftershocks result from the direct effect of coseismic stress change on a population of nucleating faults with a rate-weakening rheology. So postseismic relaxation expressed in seismicity or geodesy would relate to different mechanisms. In the present paper, we show that postseismic deformation measured from GPS and aftershocks following the Chi-Chi earthquake, Taiwan, did follow the same temporal evolution consistent with triggered afterslip in the BCFZ. The development of an elaborated numerical model that would fully account for the rheological layering of the crust, including the BCFZ, is beyond the scope of this paper. We rather use a simple analytical formulation. This paper might therefore be seen as a complement, and generalization, of Marone et al.'s [1991] analysis.

[4] We first describe the simplified fault model underlying our analysis and discuss the rheology ascribed to the fault portion in brittle creep. We discuss whether the zone of brittle creep should be considered as a fault zone with finite width, characterized by some brittle creep rheology, or as a interface with velocity-strengthening friction. We show that both approaches lead to the same formalism. We next assess the response to a stress increase or dynamic stress variations. We show, in particular, that the intrinsic response of the BCFZ might provide a way to reconcile crustal postseismic relaxation and aftershocks following the 1999 ChiChi earthquake in Taiwan.

\section{Fault Model}

\subsection{Geometry}

[5] The theoretical fault zone model underlying our investigation is depicted in Figure 1. It conforms to the more general fault zone model described above [e.g., Scholz, 1990]. The particular geometry shown here was inspired from case examples of intracrustal thrust faults in the Himalaya or in Taiwan [Cattin and Avouac, 2000; Dominguez et al., 2003; H. Kao, unpublished manuscript, 2002], where some simple physical rationale was proposed to relate microseismicity and interseismic deformation. Deformation is thought to be dominated by ductile flow at depth where temperatures get higher enough to enhance dislocation creep $\left(T \gtrsim 400^{\circ} \mathrm{C}\right)$. The shallow fault portion where $T \lesssim 250^{\circ} \mathrm{C}$ is assumed to have a stick-slip behavior due to a velocity-weakening friction law. The zone of transition that connects the down-dip extent of this seismogenic zone with the zone of ductile flow, where $T$ is between 250 and $400^{\circ} \mathrm{C}$, is assumed to obey rate-strengthening brittle creep. In the interseismic period, stresses build up around the down-dip end of the locked fault portion, triggering microseismic activity in the surrounding medium at midcrustal to upper crustal levels [Cattin and Avouac, 2000]. Since this microseismic activity accounts for at most a few percent of the observed strain in the interseismic period and since it coincides with the zone of elastic straining indicated from geodetic measurements, it might be seen as reflecting slip on minor faults embedded in the deforming elastic medium. So in this particular context, seismicity rate in the interseismic period might reasonably be considered to be proportional to strain rate, as measured from geodetic measurement. This rationale might also hold for the postseismic deformation insofar as the seismic moment of aftershocks only accounts for a small fraction of the measured strain. During interseismic or postseismic deformation, the strain rate measured at the surface from geodesy, together with the seismicity rate, might be taken to be representative of elastic loading of the upper crust associated with ductile shear at depth. In the following, we will neglect the viscous response of the lithosphere due to ductile flow. We therefore assume that any stress drop on the locked fault zone is transferred to a stress increase on the BCFZ. This simplification allows us to draw some simple inferences based on some analytical considerations. A more realistic model should account for the stress transfer in three dimensions to both the BCFZ and the viscous lower crust below.

[6] In order to estimate the response of the BCFZ to a temporal stress perturbation, we use a one-dimensional (1-D) spring-block model as shown in Figure 1b. A block is loaded at constant velocity $V_{0}$, and the elastic response of the medium surrounding the brittle creep section of characteristic size $H$ is modeled by a spring with stiffness $k$ :

$$
k=\frac{G}{H},
$$

where $G$ is the shear modulus of the medium. The equivalent stiffness $k$ depends slightly on the deformation mode and the geometry of the slipping zone [Marone et al., 1991; Dieterich, 1992]. Despite its simplicity, the 1-D spring-block model has been shown to produce results in qualitative agreement with those obtained from more elaborated 2-D models [e.g., Dieterich, 1992; Dieterich and Kilgore, 1996; Perfettini et al., 2003a, 2003b] and was therefore adopted in the present study.

\subsection{Rheology of the BCFZ: Cataclastic Flow Versus Stable Frictional Sliding}

\subsubsection{Cataclastic Flow}

[7] Observations of exhumed natural fault zones suggest that faulting at depth is accommodated by cataclastic deformation (frictional sliding between gouge fragments and fragments crushing) in association with solution transfer 

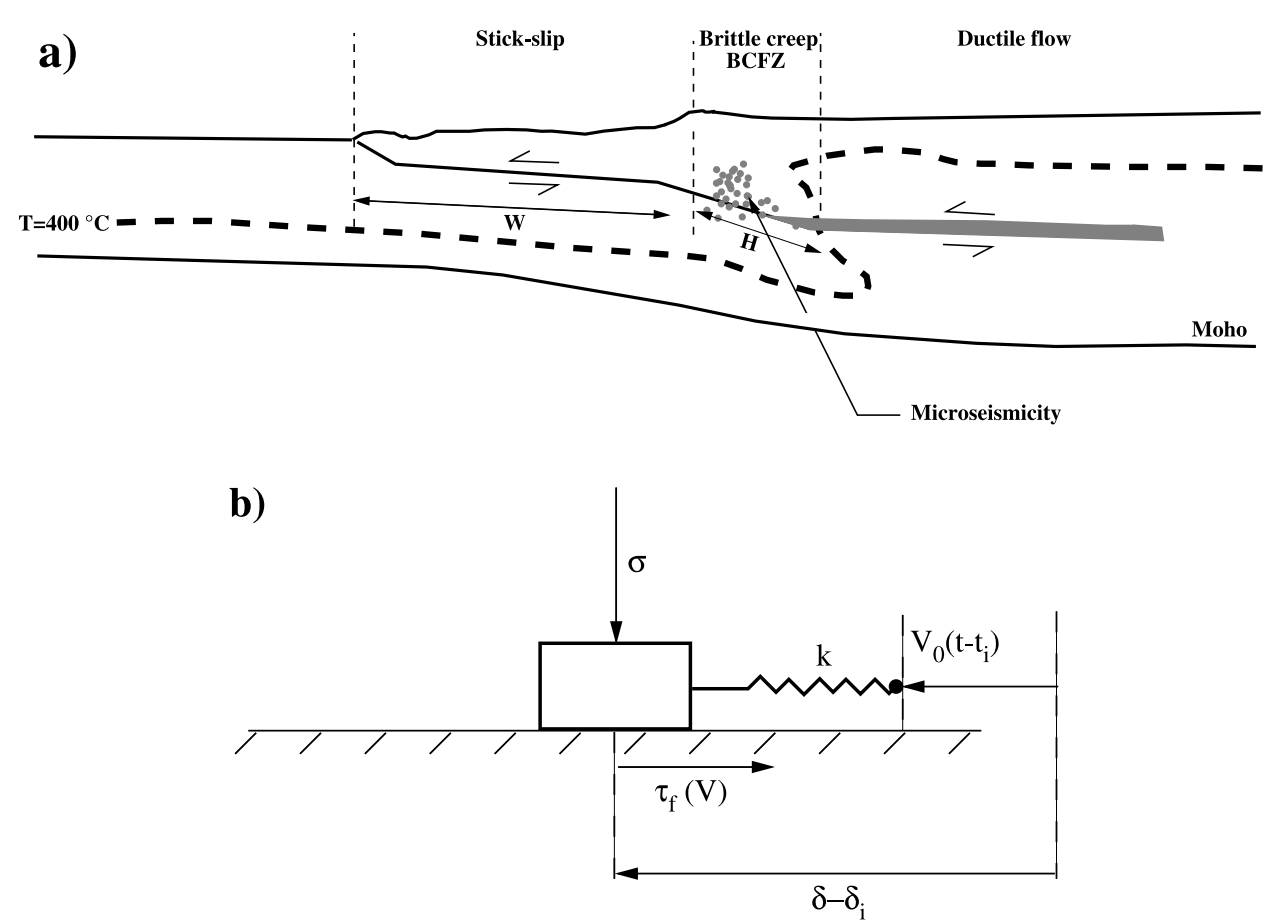

Figure 1. (a) Fault model considered in this study consisting of three main domains each of which obeys a different rheology. The upper part of the fault, where temperature is less than $250^{\circ} \mathrm{C}$, is the seismogenic zone where rate-weakening friction can allow earthquake nucleation. At depth, where temperature gets higher than about $400^{\circ} \mathrm{C}$, it roots into a ductile shear zone, governed by dislocation creep. Between these two domains, the fault rheology is assumed to obey rate-strengthening brittle creep. In the interseismic period the seismogenic fault portion is locked, while the long-term thrusting rate, $V_{0}$, is absorbed by ductile shear at depth. The slip rate tapers in the BCFZ dominated by stable brittle creep. In that setting, seismicity is driven by stress buildup near the down-dip end of the locked fault zone as observed in the Himalaya [Cattin and Avouac, 2000] and in Taiwan [Dominguez et al., 2003]. (b) Springslider model used to derive the analytical expression of transient slip along the BCFZ.

processes [e.g., Chester, 1995]. These observations have prompted the view that faults rheology should be interpreted in terms of brittle creep of a fluid-saturated fault gouge [Chester, 1995; Sleep, 1995]. Brittle creep has long been known in soil mechanics [Mitchell, 1976]. It is a pressuresensitive mechanism that implies porosity changes due to collapse of initial porosity (for a relatively porous initial sample) and porosity increases associated with dilatancy. The micromechanical processes associated with these phenomena have received some attention in the geophysical literature, and some authors have derived theoretical fault models [Marone et al., 1990; Sleep, 1995, 1997; Segall and Rice, 1995; Main, 2000]. In triaxial "creep tests" in which a sample is submitted to a constant axial force and a symmetric confining pressure, the strain-stress curve generally shows three domains. A first period of decelerating "primary" creep is followed by some steady state "secondary" creep until some accelerating "tertiary" creep that ultimately leads to failure by static fatigue. It has been shown that the entire creep process, including primary, secondary, and tertiary creep, can be modeled from some thermodynamical analysis (based on a single thermoactivated process) providing theoretical support to these empirical laws [Fish, 1984]. Throughout the interseismic period, secondary creep would be the dominant process. Many empirical laws can be found in the literature. They generally propose a power law or exponential law dependence of strain rate on stress. For example, on the basis of triaxial compressional tests on drained and undrained soils, Singh and Mitchell [1968] have obtained

$$
\frac{d \epsilon}{d t}=A_{1} \exp \left(A_{2} D\right)\left(\frac{t_{1}}{t}\right)^{m},
$$

where $A_{1}, A_{2}, t_{1}$, and $m$ are some empirical constants to be determined experimentally, $d \epsilon / d t$ is the strain rate, and $D$ is given by

$$
D=\frac{\left(\sigma_{1}-\sigma_{3}\right)}{\left(\sigma_{1}-\sigma_{3}\right)_{f}},
$$

where $\left(\sigma_{1}-\sigma_{3}\right)_{f}$ is the deviatoric stress at rupture and $\left(\sigma_{1}-\right.$ $\sigma_{3}$ ) is the deviatoric stress at time $t$, both quantities being proportional to the effective confining pressure. Equation (3) can be written as

$$
\begin{aligned}
\left(\sigma_{1}-\sigma_{3}\right)= & \frac{\left(\sigma_{1}-\sigma_{3}\right)_{f}}{A_{2}}\left[-\log \left(A_{1}\right)-m \log \left(t_{1}\right)\right. \\
& +\log (d \epsilon / d t)+m \log (t)] .
\end{aligned}
$$


Therefore, prior to rupture the shear stress $\tau$ would relate to the velocity $V \propto d \epsilon / d t$ and the time $t$ and the effective normal stress $\sigma$ according to some equation of the form

$$
\tau=\sigma\left[A_{3}+A_{4} \log (V)+A_{5} \log (t)\right]
$$

where $A_{3}, A_{4}$, and $A_{5}$ are some empirical constants.

[8] The time dependence only plays a role during primary creep. During steady sate sliding, the time dependence can be neglected so that

$$
\tau \simeq \sigma\left[A_{6}+A_{4} \log (V)\right]
$$

A similar brittle creep law, with some exponential dependence of strain rate on deviatoric stresses, has been obtained from intact granite rocks, in which brittle creep is probably controlled by subcritical crack growth [Lockner, 1998], showing that this kind of law probably holds for a wide range of cases.

\subsubsection{Frictional Sliding}

[9] The formalism in equation (5) might also be compared with the rate-and-state formalism deduced from sliding experiments. Whether faulting should be interpreted in terms of frictional sliding along an interface or deformation distributed within a fault gouge with finite width has long been a matter of debate. The two approaches are reconcilable since rate-and-state friction laws, initially developed from sliding experiments with bare surfaces [e.g., Dieterich, 1979; Ruina, 1983; Baumberger et al., 1995; Dieterich and Kilgore, 1996], seem to still hold in experiments conducted with a synthetic wet or dry gouge [e.g., Marone et al., 1990; Blanpied et al., 1995; Chester, 1995] and are also consistent with constitutive brittle creep laws established for intact rocks [Lockner, 1998]. Also, the two approaches can be reconciled from theoretical considerations [Sleep, 1995].

[10] According to these experiments the shear stress during frictional sliding, $\tau_{f}$, obeys

$$
\tau_{f}(V, \theta)=\sigma\left[\mu *+a \log \left(\frac{V}{V_{*}}\right)+b \log \left(\frac{\theta V_{*}}{D_{c}}\right)\right],
$$

where $\sigma$ is the effective normal stress, $V$ is the sliding velocity, and $\theta$ is a variable describing the "state" of the surface; $a, b, D_{c}$, and $\mu_{*}$ are some frictional parameters, and $V_{*}$ is defined such that the friction coefficient is $\mu_{*}$ when the fault slides at steady velocity $V_{*}$.

[11] The evolution of the state variable with time is given by

$$
\frac{d \theta}{d t}=1-\frac{V \theta}{D_{c}}
$$

For bare surfaces (no gouge), $\theta$ can be interpreted as the average age of the contacts between the sides of the fault [Dieterich and Kilgore, 1994; Baumberger et al., 1999], while for wet fault gouge, it might represent the difference between the actual porosity and a critical porosity corresponding to failure [Sleep, 1995].

[12] When the sliding velocity tends to 0 , we see from equation (8) that $\theta$ is given by $\theta=t+t_{0}$, where $t_{0}$ is a constant. In this case, equation (7) is identical to equation (5) used to describe brittle creep. Therefore the two approaches yield the same functional dependency on sliding velocity and time.

[13] For sliding at steady state the value of the state variable is $\theta^{s s}$ and verifies $\theta^{s s}=D_{c} / V$ such that $\dot{\theta}=0$. In this case, the shear stress at steady state, $\tau_{f}^{s s}$, is

$$
\tau_{f}^{s s}(V)=\sigma\left[\mu_{*}^{\prime}+(a-b) \log (V)\right]
$$

with

$$
\mu_{*}^{\prime}=\mu *-(a-b) \log (V *)
$$

Other evolution laws exist, but they all lead to equation (9) for sliding at steady state [Ruina, 1983; Marone, 1998].

[14] Accordingly, friction decreases with increasing velocity when $b>a$. In this velocity-weakening case, sliding is potentially unstable and may give rise to stick slip when the equivalent stiffness $k$ of the elastic medium is lower than a critical value $k_{c}$ [Rice and Ruina, 1983]. If $a>b$, the material is velocity strengthening and can only undergo steady sliding.

[15] Blanpied et al. [1995] have studied frictional slip of granite at hydrothermal conditions. They have shown that steady state friction was velocity strengthening for $0<T<$ $100^{\circ} \mathrm{C}$ and $T>250^{\circ} \mathrm{C}$, while it was velocity weakening for $100^{\circ} \mathrm{C}<T<250^{\circ} \mathrm{C}$. For temperatures higher than $250^{\circ} \mathrm{C}$, which is the temperature regime which corresponds to brittle creep in our model, the individual parameters $a$ and $b$ were poorly constrained. Therefore we will set $b=0$ in our work as previously proposed by Rice [1993]. Doing so, we only consider a rate dependence of friction and neglect the state dependence. Note that Blanpied et al. [1995] found $a=0.02$ as a representative value when $T>250^{\circ} \mathrm{C}$.

\subsubsection{Constitutive Law for the BCFZ}

[16] With our choice of $b=0$, the velocity-dependent frictional law turns out to be like that inferred from steady state brittle creep or "secondary creep" (see equation (6)). So, the dependency of shear stress on slip rate might generally be written

$$
\tau_{f}(V)=\sigma\left[\mu_{*}^{\prime}+a \log (V)\right],
$$

with the coefficient $a>0$ characterizing the dependence of the strength of the material to a change in the deformation rate.

\section{Response to Stress Perturbations}

\subsection{Analytical Expression for a Spring-Slider System}

[17] We consider here only a shear stress perturbation $\Delta \tau$. In Appendix A we show that the same formalism applies to the general case of a perturbation involving both shear and normal stress changes, provided that $\Delta \tau$ is replaced by the Coulomb stress change $\triangle \mathrm{CFF}$.

[18] The equation of motion of the spring-slider (see Figure 1b) system is given by

$$
\tau_{f}(V)=\tau_{i}+k\left(V_{0} t-\delta\right)+\Delta \tau(t),
$$

where $\tau_{i}$ is the initial shear stress, $\delta$ is the slip of the block, $t$ is time, and $\Delta \tau(t)$ is the shear stress perturbations. 
(a)

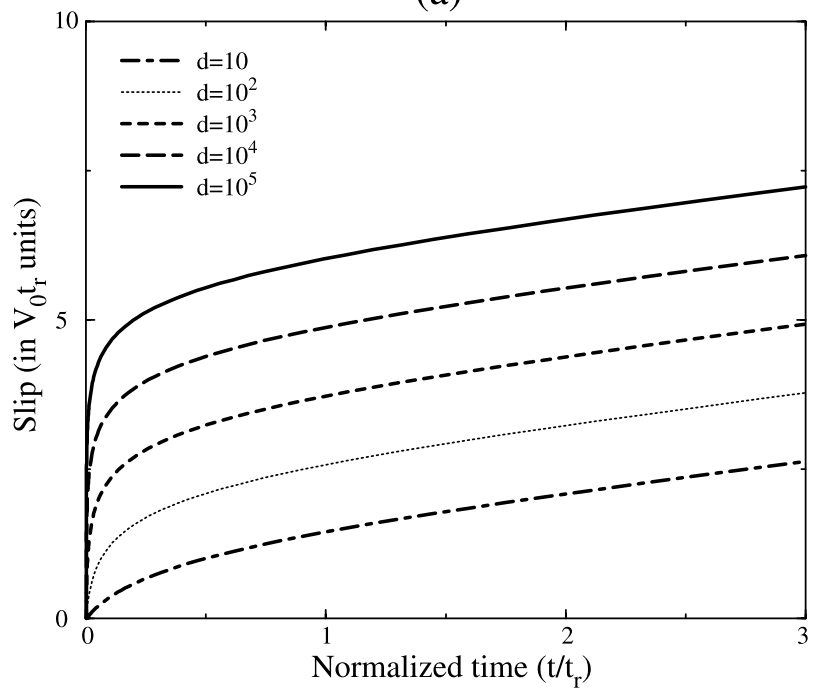

(b)

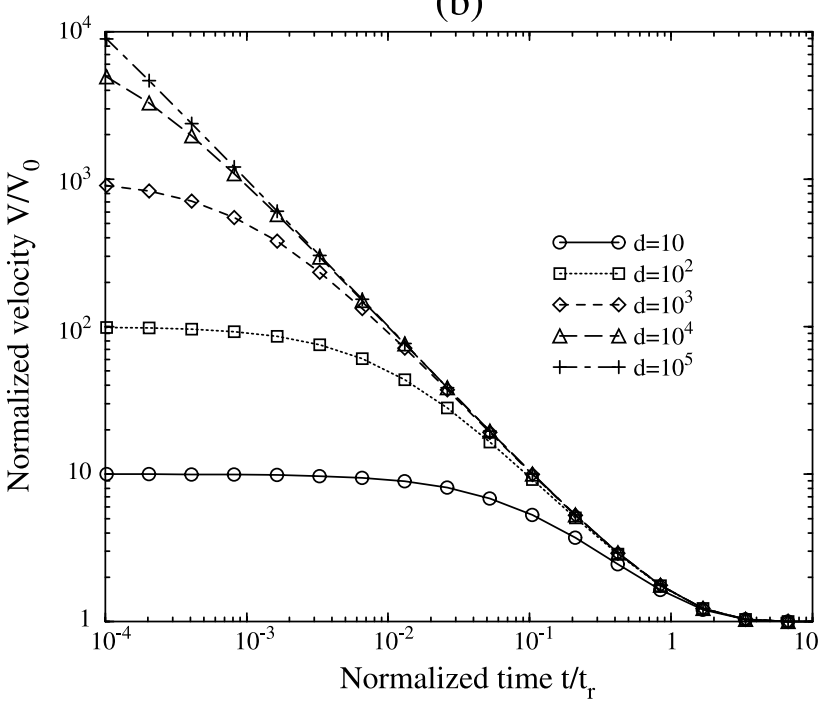

Figure 2. (a) Afterslip and (b) velocity as a function of time for various values of $d\left(10,10^{2}, 10^{3}, 10^{4}\right.$, and $10^{5}$ ).

Introducing the initial velocity, $V_{i}$, and slip, $\delta_{i}$, and given the initial stress balance

$$
\tau_{f}\left(V_{i}\right)=\tau_{i}-k \delta_{i},
$$

we get

$$
a \sigma \log \left(V / V_{i}\right)=k\left(V_{0} t-\delta+\delta_{i}\right)+\Delta \tau(t) .
$$

Introducing the slip increment $U=\delta-\delta_{i}$ and noting that $V=d \delta / d t=d U / d t$, we obtain

$$
\frac{d U}{d t}=V_{i} \exp \left[c\left(V_{0} t-U\right)+\frac{\Delta \tau(t)}{a \sigma}\right],
$$

where $c=k / a \sigma$. A characteristic time $t_{r}$ is associated with equation (15) and can be written

$$
t_{r}=\frac{a \sigma}{k V_{0}}=\frac{a \sigma}{\dot{\tau}},
$$

where $\dot{\tau}=k V_{0}$ is the interseismic shear stressing rate.

[19] After integration, equation (15) yields

$$
U(t)=\frac{1}{c} \log \left[1+c V_{i} F(t)\right],
$$

where

$$
F(t)=\int_{0}^{t} \exp \left[\frac{t^{\prime}}{t_{r}}+\frac{\Delta \tau\left(t^{\prime}\right)}{a \sigma}\right] d t^{\prime}
$$

which finally leads to

$$
\delta(t)=\delta_{i}+\frac{1}{c} \log \left[1+c V_{i} F(t)\right] .
$$

The sliding velocity $V(t)=d \delta / d t$ is therefore given by

$$
V(t)=V_{i} \frac{\exp \left[\frac{t}{t_{r}}+\frac{\Delta \tau(t)}{a \sigma}\right]}{1+c V_{i} F(t)} .
$$

Equations (19) and (20) allow one to calculate, at any time, the slip and sliding velocity of a rate-strengthening creeping zone in response to any shear stress perturbations. Accordingly, any stress perturbation is expected to induce a change in the sliding velocity, which remains finite, that relaxes and tend back to $V_{0}$ once the perturbation has stopped. This is a reasonable assumption to estimate afterslip provided that $t_{r}$ is large compared to the characteristic duration of the seismic wave train. As shown below (see section 5 for an estimate of $t_{r}$ for the Chi-Chi earthquake), this is probably a reasonable assumption.

[20] Let us now consider the particular case of a sudden shear stress increase, i.e., $\Delta \tau(t)=\Delta \tau H(t)$, where $H(t)$ is the Heaviside function. For such a perturbation the function $F(t)$ defined in equation (18) is

$$
F(t)=t_{r} d\left[\exp \left(t / t_{r}\right)-1\right],
$$

where

$$
d=\exp (\Delta \tau / a \sigma) .
$$

A coseismic shear stress change $\Delta \tau$ at time $t=0$ should produce a discontinuity of the sliding velocity which increases (or decreases) by a factor $d$. Using equation (19) and (21), we obtain

$$
\delta(t)=\delta_{i}+\frac{1}{c} \log \left[1+d \frac{V_{i}}{V_{0}}\left(\exp \left(t / t_{r}\right)-1\right)\right],
$$

while the velocity follows

$$
V(t)=V_{i} \frac{d \exp \left(t / t_{r}\right)}{1+d \frac{V_{i}}{V_{0}}\left(\exp \left(t / t_{r}\right)-1\right)} .
$$

In Figures $2 \mathrm{a}$ and $2 \mathrm{~b}$ we show the characteristic time evolution of slip and velocity for various values of $d$.

\subsection{Comparison With Marone et al.'s [1991] Formulation}

[21] Here, we compare our formulation with that proposed by Marone et al. [1991], who also considered a 1-D spring-slider model with rate-and-state friction to model 


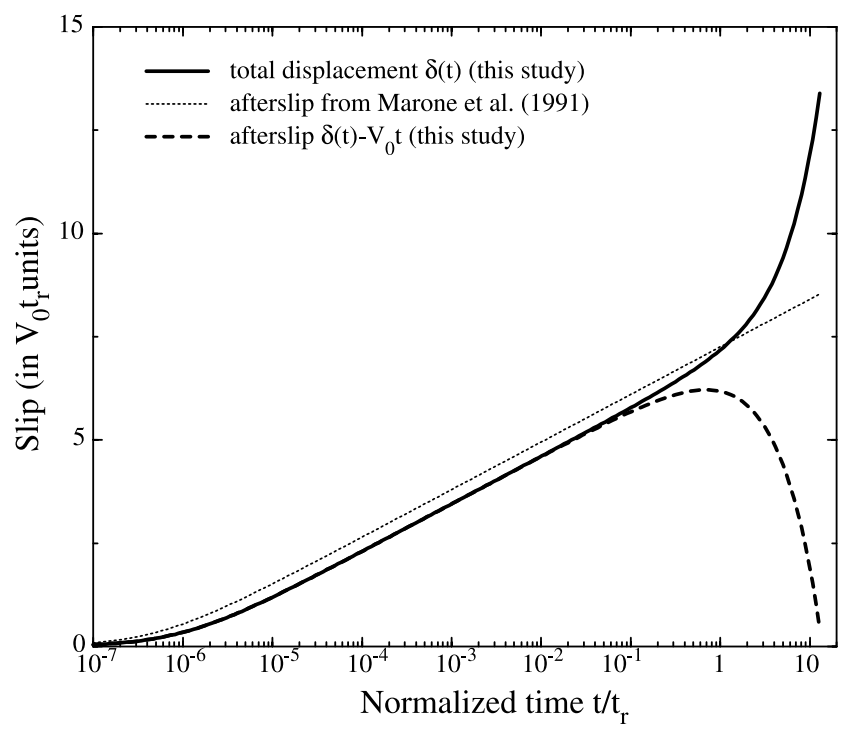

Figure 3. Slip as a function of time. The straight line corresponds to the total displacement field predicted by our model which diverges as $V_{0} t$ at large times. The long dashed line shows the contribution of the afterslip process alone derived from our model. This afterslip becomes significantly small for times greater than $t_{r}$, unlike the afterslip predicted by Marone et al. [1991] (see the dotted line) which diverges at large times. The three curves are in close agreement for times lower than $t_{r}$, since the contribution of the interseismic loading can be neglected.

shallow afterslip. They obtained that in response to an increase in the sliding velocity from $V_{0}$ to $V_{c s}$, equivalent to a stress step $\Delta \tau$ given by

$$
\Delta \tau=a \sigma \log \left(V_{c s} / V_{0}\right),
$$

the postseismic slip $\delta_{p}(t)$ should follow [see Marone et al., 1991, equation (5)]:

$$
\delta_{p}(t)=\alpha \log \left[\frac{V_{c s} t}{\alpha}+1\right],
$$

with

$$
\alpha=\frac{a \sigma}{k} .
$$

Equation (23) can be written for comparison using the notations of Marone et al. [1991] with $V_{i}=V_{0}$ since the fault is assumed to be creeping at long-term velocity prior to the perturbation

$$
\delta(t)-\delta_{0}=\alpha \log \left\{1+\frac{V_{c s}}{V_{0}}\left[\exp \left(V_{0} t / \alpha\right)-1\right]\right\} .
$$

At "small" times, namely, $t \ll t_{r}=\alpha / V_{0}$, equation (28) simplifies to

$$
\delta(t)-\delta_{0} \simeq \alpha \log \left[1+\frac{V_{c s} t}{\alpha}\right]=\delta_{p}(t),
$$

which is the formulation of Marone et al. [1991]. However, our formulation is more general since it allows determination of the response of the system to any stress perturbations and remains valid throughout the interseismic period. The two expressions (equations (23) and (26)) are compared graphically in Figure 3. It should be noticed that our model predicts an afterslip that cannot exceed $\Delta \tau / k$, while this physical requirement is not met by the formulation of Marone et al. [1991].

\section{Implication for Aftershocks}

\subsection{Seismicity Rate Change Following an Arbitrary Stress Perturbation}

[22] As argued in section 2.1, we assume that the postseismic response of the BCFZ drives aftershocks, the seismicity rate around the tip of the creeping zone being proportional to the stress rate. We assume that the stress rate depends primarily on the slip rate along the BCFZ. There must also be some contribution from the zone of ductile flow at depth, but this term may be considered to be in steady state since the characteristic time of viscous relaxation is probably much longer than the one associated with deep afterslip. In that case, referring to the more general formulation derived in Appendix A (equation (A15)) which deals with shear and normal stress changes, the seismicity rate may be written

$$
R(t)=R_{0}\left(V_{i} / V_{0}\right) \frac{\exp \left[\frac{t}{t_{r}}+\frac{\Delta \mathrm{CFF}(t)}{a \bar{\sigma}}\right]}{1+c^{G} V_{i} F^{G}(t)},
$$

where the function $F^{G}(t)$ that accounts for the stress perturbations is given in equation (A10) and $R_{0}$ corresponds to the background seismicity rate during interseismic stress buildup. The function $\Delta \operatorname{CFF}(t)$ represents the Coulomb stress changes induced by the main shock and related to shear and normal stress changes through equation (A1). Equation (30) determines the seismicity rate change following any stress perturbations, assuming that seismicity is triggered by the postseismic relaxation of the BCFZ. It should be realized that this formulation is correct only if the nonelastic deformation resulting from the aftershocks remains small compared to total postseismic deformation. Finally, it should be noted that according to this formulation, the seismicity rate change is sensitive to the stress perturbation through the factor $\exp [\Delta \mathrm{CFF}(t) / a \bar{\sigma}]$ and the function $F^{G}(t)$. Estimating seismicity rate change from real data is not straightforward. A more robust quantity reflecting the seismicity rate change is the cumulated number $N(t)$ of earthquakes, which should follow

$$
N(t)=N(t=0)+R_{0} t_{r} \log \left[1+\frac{V_{i}}{V_{0} t_{r}} F^{G}(t)\right],
$$

where $N(t=0)$ is the cumulated number of earthquakes at time $t=0$. In the case of a stress step in Coulomb stress of amplitude $\triangle \mathrm{CFF}$ occurring at $t=0$ on a BCFZ creeping at an initial velocity $V_{i}$, the cumulated number of earthquakes at later times is given by

$$
N(t)=N(t=0)+R_{0} t_{r} \log \left[1+\left(V_{i} / V_{0}\right) d^{G}\left(\exp \left(t / t_{r}\right)-1\right)\right],
$$

using equation (A17) with $\Delta t=0$ and $d^{G}=\exp [\Delta \mathrm{CFF} /$ $(a \bar{\sigma})]$. 


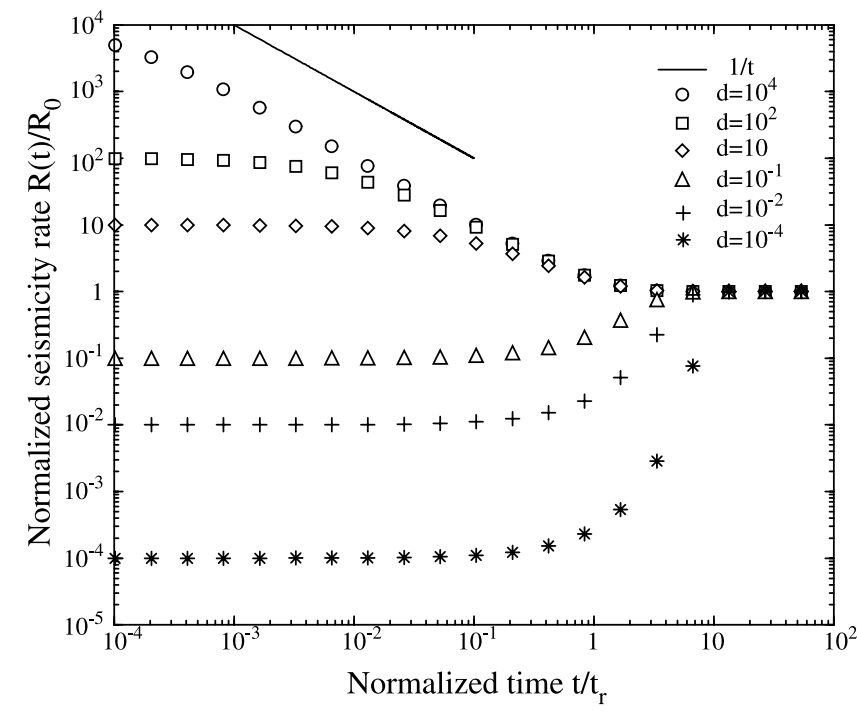

Figure 4. Seismicity rate change following a step in shear stress of various amplitudes $\left(d=10^{4}, 10^{2}, 10^{-2}\right.$, and $\left.10^{-4}\right)$ for $c=100$. The characteristic time for the aftershock duration is $t_{r}$. Note that the decrease in seismicity rates (due to a decrease in the shear stress) lasts longer than increase in seismicity rates (due to an increase in shear stress).

[23] Also note that for practical use, the seismicity rate $R\left(t=0^{+}\right)$immediately after any stress step characterized by $d^{G}$ relates to the seismicity rate $R\left(t=0^{-}\right)$immediately before so that $R\left(t=0^{+}\right)=d^{G} R\left(t=0^{-}\right)$. So, equation (32) may also be written

$$
N(t)=N(t=0)+R_{0} t_{r} \cdot \log \left[1+\frac{R\left(t=0^{+}\right)}{R_{0}}\left[\exp \left(t / t_{r}\right)-1\right]\right]
$$

Figure 4 shows the evolution of the normalized seismicity rate in response to Coulomb stress steps of various amplitude $\left(d=10^{4}, 10^{2}, 10^{-2}\right.$, and $\left.10^{-4}\right)$. After an elapsed time of the order of $t_{r}$, the seismicity rate returns to its background value $R_{0}$. In the case of an increase of the Coulomb stress $(d>1)$, the seismicity rate shows a $1 / t$ decay in agreement with the empirical Omori's law of aftershocks. This important feature will be discussed in section 4.2.

\subsection{Consistency With Omori's Law}

[24] Omori Using equation (30) with the Coulomb stress given in equation (A16), we obtain, after use of equation (A17),

$$
\begin{aligned}
R(t)= & R_{0}\left(V_{i} / V_{0}\right) \\
& \cdot \frac{\exp \left[\frac{t}{t_{r}}+\frac{\Delta \mathrm{CFF}(t)}{a \bar{\sigma}}\right]}{1+c^{G} V_{i}\left\{F^{G}(\Delta t)+t_{r} d^{G}\left[\exp \left(t / t_{r}\right)-\exp \left(\Delta t / t_{r}\right)\right]\right\}} .
\end{aligned}
$$

Once the dynamic stress field has vanished, i.e., when $t>$ $\Delta t$, the only stress field that is left is the static Coulomb stress field $\Delta \mathrm{CFF}^{s}(t)=\Delta \mathrm{CFF}^{s} H(t-\Delta t)$. After the change of variable $t^{\prime}=t-\Delta t$, equation (34) becomes

$$
\begin{aligned}
R\left(t^{\prime}\right)= & R_{0}\left(V_{i} / V_{0}\right) \\
& \cdot \frac{d^{G} \exp \left(\frac{\Delta t}{t_{r}}\right) \exp \left(\frac{t^{\prime}}{t_{r}}\right)}{1+c^{G} V_{i} F^{G}(\Delta t)+c^{G} V_{i} t_{r} d^{G} \exp \left(\Delta t / t_{r}\right)\left[\exp \left(t^{\prime} / t_{r}\right)-1\right]} \\
& \cdot \forall t^{\prime}>0 .
\end{aligned}
$$

At small times after the end of the dynamic stress field, namely, $t^{\prime} \ll t_{r}$, the seismicity rate is

$$
R\left(t^{\prime}\right) \simeq \frac{R_{0}}{c^{G} V_{0}}\left\{\left[\frac{1+c^{G} V_{i} F^{G}(\Delta t)}{c^{G} V_{i} d^{G} \exp \left(\Delta t / t_{r}\right)}\right]+t^{\prime}\right\}^{-1} .
$$

Thus equation (36) takes the form of the empirical Omori's law of aftershocks decay rate

$$
R(t)=\frac{a_{1}}{b_{1}+t},
$$

where $a_{1}$ and $b_{1}$ are some constants determined empirically. Within the framework of our model these constants would be

$$
\begin{gathered}
a_{1}=\frac{R_{0}}{c^{G} V_{0}}=R_{0} t_{r} \\
b_{1}=\frac{1+c^{G} V_{i} F^{G}(\Delta t)}{c^{G} V_{i} d^{G} \exp \left(\frac{\Delta t}{t_{r}}\right)} .
\end{gathered}
$$

\subsection{Comparison With the Model of Dieterich [1994]}

[25] In this section we compare our interpretation of aftershock decay with the formulation of Dieterich [1994]. Dieterich considered a population of faults in the selfaccelerating phase (so that $d \theta / d t \simeq-V \theta / D_{c}$ in equation (8) and therefore only the slip-weakening influence of $\theta$ is considered), which are not interacting, assuming the existence of a steady state background seismicity rate $R_{0}$. On the basis of these assumptions, he derived the initial velocity distribution of such faults in order to have the constant seismicity rate $R_{0}$ prior to the stress perturbation. When the perturbation is applied, the velocity distribution is modified, and these faults are brought, depending on the Coulomb stress variation, closer to or farther away from failure. For a Coulomb stress increase on a given population of faults, this mechanism leads to an increase of the seismicity rate followed by some decay according to

$$
R(t)=\frac{R_{0}}{\gamma(t) \dot{\tau}}
$$

where $\dot{\tau}$ is the reference stressing rate. The variable $\gamma$ accounts for the stress variations

$$
\frac{d \gamma}{d t}=\frac{1}{a \sigma}\left[1-\gamma \frac{d \tau}{d t}+\gamma\left(\frac{\tau}{\sigma}-\alpha\right) \frac{d \sigma}{d t}\right]
$$

where $\tau(\sigma)$ is the total shear (normal) stress and $\alpha$ is a frictional parameter that takes into account the response of 
the interface to normal stress variations [Linker and Dieterich, 1992]. Because the potential effect of normal stress variations is not explicitly taken into account in our analytical approach above, we draw a parallel between Dieterich's model and ours in the particular case $\alpha=0$.

[26] Actually, it can be shown that although based on radically different physical rationale, our model predicts the same evolution laws as equation (41). The seismicity rate given in equation (30) can be written as

$$
R(t)=\frac{R_{0}}{g(t) k V_{0}},
$$

the function $g(t)$ being given by

$$
\begin{gathered}
g(t)=\left(\frac{1}{k V_{i}}\right) \exp \left[\frac{-t}{t_{r}}+\frac{-\Delta \operatorname{CFF}(t)}{a \bar{\sigma}}\right] \\
\cdot\left[1+c^{G} V_{i} F^{G}(t)\right],
\end{gathered}
$$

where $F^{G}(t)$ can be calculated using equation (A10) and $\triangle \mathrm{CFF}(t)$ is the perturbation in the Coulomb stress. The derivative of $g(t)$ with respect to time reads

$$
\frac{d g(t)}{d t}=\frac{c^{G}}{k}-g(t)\left[\frac{1}{t_{r}}+\frac{1}{a \bar{\sigma}} \frac{d(\Delta \mathrm{CFF}(t))}{d t}\right] .
$$

Since the total shear stress is given by $\tau(t)=\tau_{i}+\dot{\tau} t+\Delta \tau(t)$ with $\dot{\tau}=k V_{0}, \tau_{i}$ being the initial shear stress, we get

$$
\frac{d(\Delta \tau(t))}{d t}=\frac{d \tau}{d t}-\dot{\tau},
$$

and considering the normal stress, we get

$$
\frac{d(\Delta \sigma(t))}{d t}=\frac{d \sigma}{d t} .
$$

Using equations (45), (46) and (A1) in (44) leads to

$$
\frac{d g(t)}{d t}=\frac{c^{G}}{k}-g(t)\left[\frac{1}{t_{r}}-\frac{\dot{\tau}}{a \bar{\sigma}}+\frac{1}{a \bar{\sigma}}\left(\frac{d \tau}{d t}-\mu_{*} \frac{d \sigma}{d t}\right)\right] .
$$

Using equations (A9) and (A12), we obtain

$$
\frac{d g(t)}{d t}=\frac{1}{a \bar{\sigma}}\left[1-g(t) \frac{d \tau}{d t}-\mu_{*} g(t) \frac{d \sigma}{d t}\right] .
$$

Equation (48) has the same form as equation (41) for $\alpha=0$ and noting that $\tau / \sigma \simeq \mu_{*}$.

[27] Our formulation can be easily extended to $\alpha \neq 0$ noting that changing $\mu_{*}$ by $\mu_{*}-\alpha$ removes the term $\alpha$ in equation (41). Practically the only change in the formalism that we presented earlier is that the Coulomb stress change has to be estimated using $\Delta \operatorname{CFF}(t)=\Delta \tau(t)-\left(\mu_{*}-\alpha\right)$ $\Delta \sigma(t)$ instead of equation (A1).

[28] Therefore we can identify the variable $\gamma(t)$ introduced by Dieterich [1994] with the function $g(t)$ defined in equation (43). Physically, the variable $\gamma(t)$ in Dieterich's work is proportional to the inverse of the sliding velocity (or "slowness") of the BCFZ in our model. So the two models lead to the same mathematical formalism. In both models, the term $a$ represents the direct velocity effect in the friction law. Since those two models are based on different physical assumptions, this convergence might seem paradoxical. The most surprising result in the work of Dieterich [1994] is that even though the strength of each individual fault depends on the state variable $\theta$ (see equation (7)), the evolution of the seismicity rate no longer contains any information about this variable since the term $b$ no longer appear at the end of the calculation. The assumption of the existence of a constant seismicity rate prior to the stress changes is probably the key assumption that removes the dependence on the state variable $\theta$. Indeed, only the dependence in $\theta$ is responsible for the slip instability, since the "viscous" term $a \log (V)$, which is rate strengthening, tends to stabilize slip. In spite of their differences both models show that the viscous term governs the decay rate of aftershocks. However, we point out that in Dieterich's model the "viscous term that controls the aftershock decay" relates to the friction parameter of the faults rupturing during the aftershock sequence, while in our model it relates to the friction parameter of the BCFZ. Note that one could envision a more complex model in which the faults in the zones of aftershocks would obey rate-weakening friction and would be submitted to a decaying stress rate due to the response of the BCFZ. Dieterich's model and the BCFZ model would then stand as end-member cases.

\section{Application to the 1999 Chi-Chi Earthquake 5.1. Parameters of the Model for the Chi-Chi Earthquake}

[29] Here we test the model taking advantage of the numerous data acquired following the 1999 Chi-Chi earthquake, $M_{w}=7.6$ in Taiwan. This earthquake broke a major thrust fault along the western foothills of the Central Range (Figure 5). The earthquake induced surface ruptures extending over $80 \mathrm{~km}$ along the Chelungpu fault trace with coseismic slip as large as $11 \mathrm{~m}$ at some places [Chen et al., 2001; Dominguez et al., 2003]. Waveform inversion and geodetic data indicate that coseismic slip that occurred on shallow $20-35^{\circ}$ east dipping ramp released a moment estimated between 2.9 and $3.410^{20} \mathrm{~N} \mathrm{~m} \mathrm{[Ma} \mathrm{et} \mathrm{al.,} \mathrm{2001;}$ Ji et al., 2001; Johnson et al., 2001; Dominguez et al., 2003]. The fault soles out into a low dipping décollement at a depth of about $6-8 \mathrm{~km}$. Geodetic measurements acquired before the earthquake indicate rapid horizontal shortening in a direction roughly perpendicular to the trend of the orogenic belt and close to the $\mathrm{N} 306^{\circ} \mathrm{E}$ plate convergence azimuth [Yu et al., 1997]. This pattern can be interpreted as due to aseismic shear beneath the Central Range, as schematized in Figure 1, while the fault portion that ruptured during the ChiChi earthquake would have remained locked [Loevenbruck et al., 2001; Dominguez et al., 2003].

[30] The main shock was followed by a sequence of aftershocks mainly concentrated along the down-dip continuation of the ruptured fault [ $\mathrm{Ji}$ et al., 2001; H. Kao, unpublished manuscript, 2002]. Rapid postseismic deformation was also measured after the earthquake [Yu et al., 2001] (Figure 6) and was shown to require afterslip on the décollement down dip of the ruptured fault portion, in the depth range of $8-12 \mathrm{~km}$ [Yu et al., 2001]. The afterslip distribution 


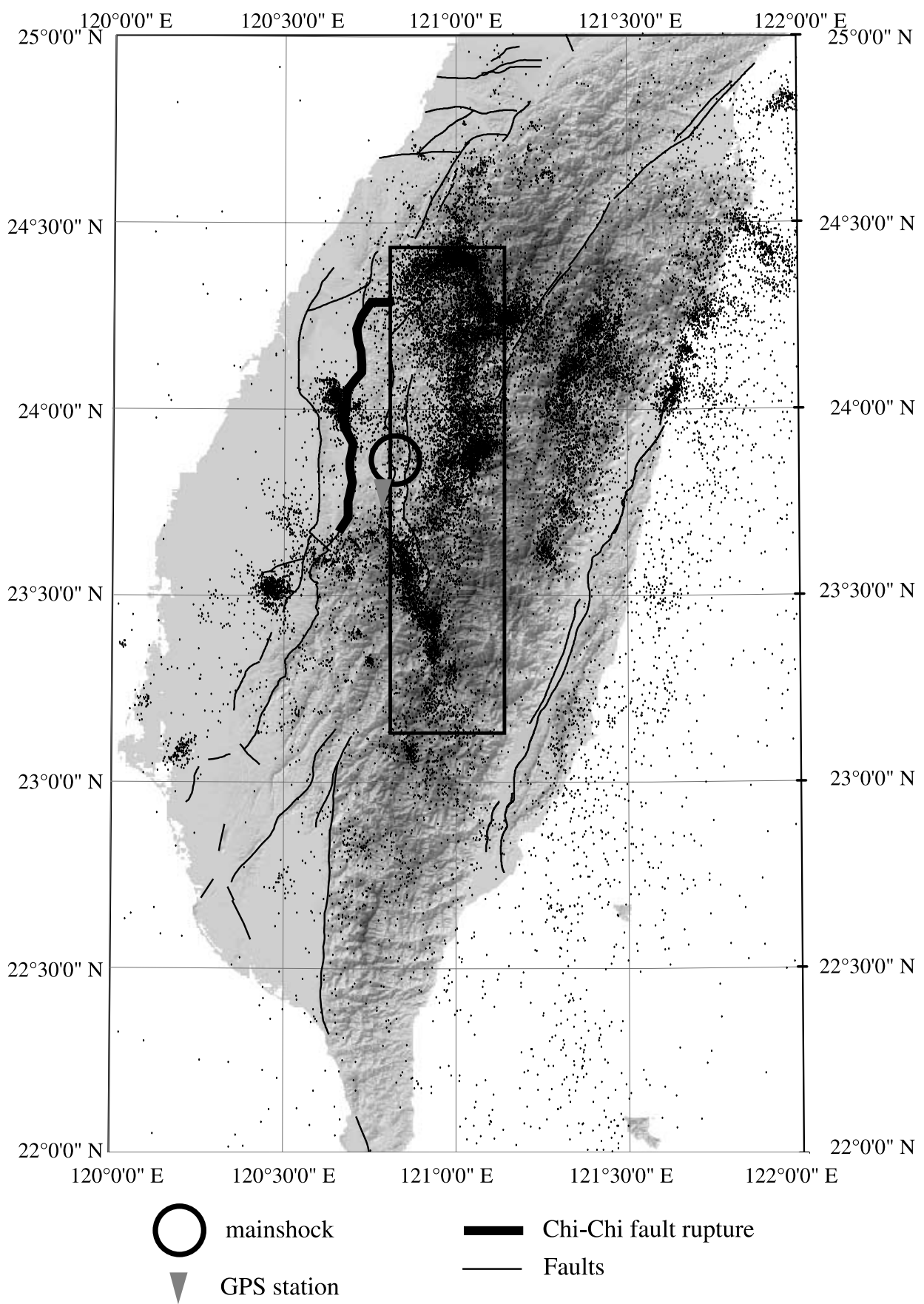

Figure 5. Location of the 1999 Chi-Chi earthquake, $M_{w}=7.6$ in Taiwan, and of GPS station I007. Aftershocks (dates, $M_{L}>2.5$ ) from Lee [2001]. Box shows the area considered within which cumulated number of earthquakes was measured.

shows maximum slip of $25 \mathrm{~cm}$ in the hypocentral area. For the purpose of this study we have used the postseismic relaxation measured at GPS station I007 (see Figure 5) as discussed by $Y u$ et al. [2001]. Velocity at this station was determined from both campaign measurements before the earthquake and continuous measurements. Before the main shock, this station was moving by about $15.8 \mathrm{~mm} / \mathrm{yr}$ toward $296^{\circ} \mathrm{E}$ with respect to some reference point on the footwall far from any effect of interseismic loading. During the earthquake it moved by $85 \pm 1.1 \mathrm{~cm}$ toward $313^{\circ} \mathrm{E}$, and its eastward displacement increased by about $20 \mathrm{~cm}$ over about 200 days (Figure 6).

[31] The seismicity rate in the zone of aftershocks does shows a coeval decay (Figure 7). The cumulated seismic moment during the aftershock sequence is of the order of $1.6 \times 10^{19} \mathrm{~N} \mathrm{~m}$ and is small in comparison to the straining of the upper crust measured over this period [Hsu et al., 2002]. It therefore makes sense to interpret the displacement measured at the surface as being due to the elastic deformation of the upper crust driven by deep afterslip. For the 


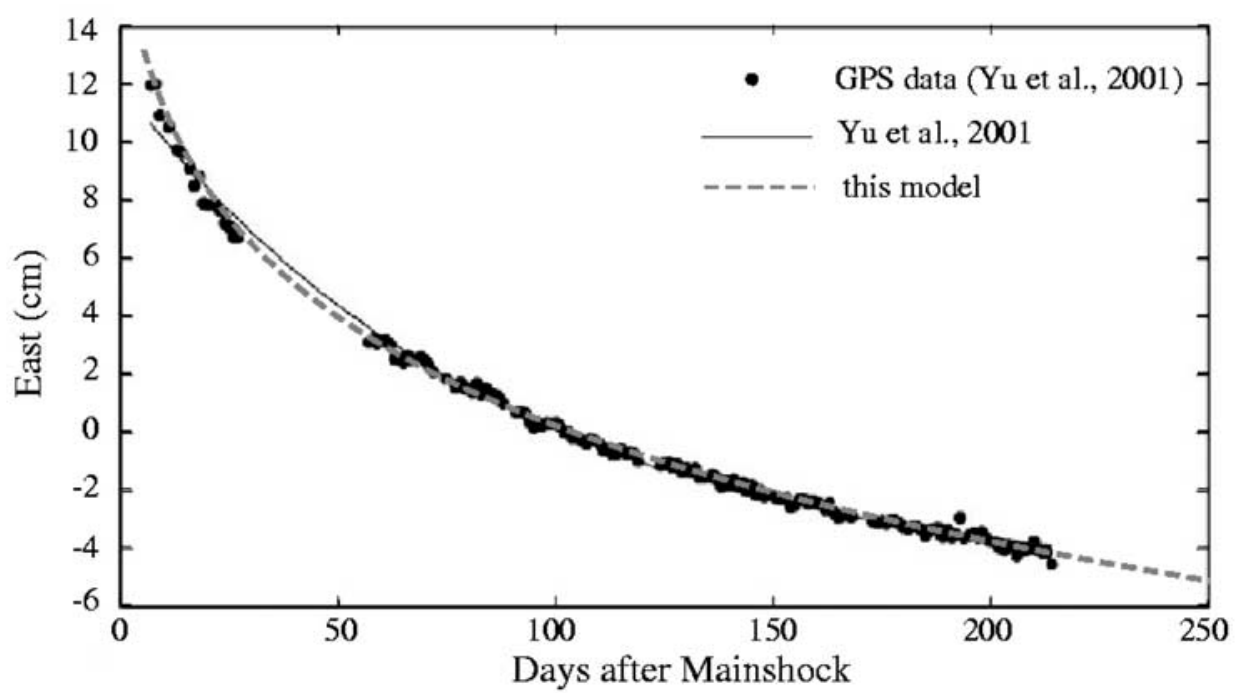

Figure 6. Postseismic eastward displacement at station I007 following the Chi-Chi earthquake [from $Y u$ et al., 2001]. See Figure 5 for location of the GPS station. The thin line represents the fit of $Y u$ et al. [2001]. The parameters used in our model (thick line) are the ones given by the inversion of the cumulated number of earthquakes with $M_{L}>2.5$ (see Figure 7), i.e., $t_{r}=8.5$ years and $d=640$. The model (thick line) is in good agreement with the data if the coseismic slip is $\Delta U_{\text {cos }}=17.2 \mathrm{~cm}$, the longterm sliding velocity of the BCFZ is $V_{1}=\beta V_{0}=6.6 \mathrm{~mm} / \mathrm{yr}$, and the long-term sliding velocity of the ductile portion of the crust is $\alpha V_{0}=7.6 \mathrm{~mm} / \mathrm{yr}$, both toward west.

purpose of the modeling, we will consider that the motion at station I007 results from two terms. One is due to ductile flow at depth. Although this term may have varied during relaxation, as assumed in viscoelastic models of postseismic relaxation, we assume a constant value. The slip rate at depth is estimated to $V_{0} \simeq 40 \mathrm{~mm} / \mathrm{yr}$ [Dominguez et al., 2003], but the contribution of this mechanism to the displacement at I007 cannot be constrained tightly because it depends on the position of the updip termination of the ductile flow zone. Therefore we assume that the velocity measured at station I007 and due to ductile flow is an unknown fraction, $\alpha$, of the velocity at depth $V_{0}$. The other term is the contribution of the BCFZ, which is assumed to control the postseismic relaxation. This zone might be seen as a transition zone along which the slip rate in the interseismic period tapers from $V_{0}=40 \mathrm{~mm} / \mathrm{yr}$ (for continuity with ductile flow at depth) to $0 \mathrm{~mm} / \mathrm{yr}$ at the down-dip end of the locked fault portion. The steady state creep rate on the BCFZ, $V_{1}$, must therefore be a fraction, $\beta$, of the long-term slip rate $(40 \mathrm{~mm} / \mathrm{yr})$.

[32] So we get that before the earthquake the eastward displacement at $\mathrm{I} 007$ relative to the footwall might be written

$$
U(t)=\alpha V_{0} t+\beta V_{0} t,
$$

with $\alpha V_{0}+\beta V_{0}=15.8 \sin \left(296^{\circ}\right)=14.2 \mathrm{~mm} / \mathrm{yr}$ toward east [Yu et al., 2001]. According to our model the postseismic response should then be written

$$
U(t)=\alpha V_{0} t+\beta V_{0} t_{r} \log \left[1+d\left(\exp \left(t / t_{r}\right)-1\right)\right],
$$

where $\alpha$ and $\beta$ are some geometric factor and

$$
d=\exp [\Delta \mathrm{CFF} /(a \bar{\sigma})]
$$

$\triangle \mathrm{CFF}$ being the static Coulomb stress change due to the main shock. The corresponding cumulated number $N(t)$ of earthquakes following the main shock should obey

$$
N(t)=N(t=0)+R_{0} t_{r} \log \left[1+d\left(\exp \left(t / t_{r}\right)-1\right)\right],
$$

where equation (32) has been used.

[33] To test the correspondence between the two sets of data, we selected the zone that might reflect seismicity triggered by stress buildup near the down-dip end of the locked fault portion (large box in Figure 5). We used the catalog of Lee [2001], which seems complete for magnitude

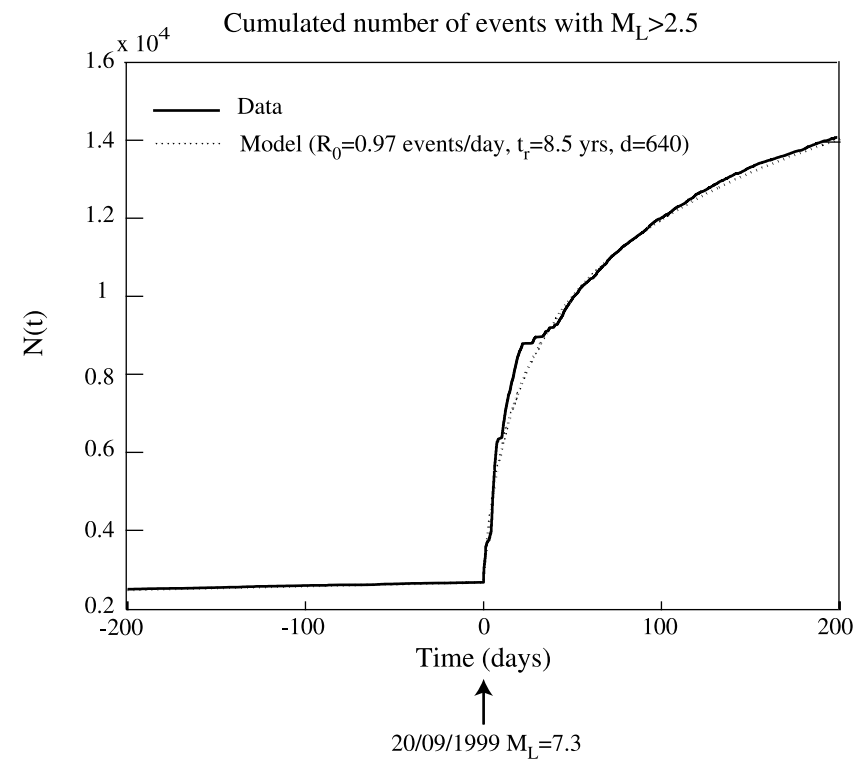

Figure 7. Cumulated number of earthquakes with $M_{L}>$ 2.5 following the Chi-Chi earthquake within the area outlined by the box in Figure 5. The model that fits the data better gives $t_{r}=8.5$ years, $d=640$ and $R_{0}=0.97$ events per day with $M_{L}>2.5$. 
above $M_{L}>2.5$, and determine the cumulated number of events above that threshold. By trial and error, we actually found that a good fit to both data (Figures 6 and 7) can be obtained for $d=640, t_{r}=8.5$ years, $V_{1}=\beta V_{0}=6.6 \mathrm{~mm} / \mathrm{yr}$, and $\alpha V_{0}=7.6 \mathrm{~mm} / \mathrm{yr}$. This model predicts correctly the decay rate of aftershocks and the velocity at station I007 including an asymptotic value equal to the preseismic velocity as determined from pre-Chi-Chi campaign GPS measurements, i.e., $14.2 \mathrm{~mm} / \mathrm{yr}$ toward west [Yu et al., 2001].

\subsection{Discussion of the Results}

\subsubsection{Value of the Relaxation Time $t_{r}$}

[34] The characteristic relaxation time $t_{r}=8.5$ years obtained for the Chi-Chi aftershock sequence might be compared with more global analysis of earthquakes clustering. Dieterich [1994] found that the mathematical formulation of equations (40) and (41) (and hence our formulation of equation (30)) was correctly predicting the statistics deduced from the Harvard catalog. For shallow events (at depth less than $70 \mathrm{~km}$ ), he obtained a global average value for $t_{r}$ of 10.2 years, relatively close to the 8.5 year value inferred from our analysis of the Chi-Chi aftershocks. For comparison, we may also mention that [Parsons, 2002] analysis of triggered events globally obey an Omori law with a characteristic decay time typically between 7 and 11 years. So, the particular case of the Chi-Chi aftershocks is not at odds with more global analysis, and we contend that brittle creep could be a common mechanism controlling the time evolution of seismicity. However, according to the rationale proposed here, there should be some variability on $t_{r}$ depending on the local tectonic setting and the thermal structure.

\subsubsection{Value of $a \bar{\sigma}$ and $a$ Parameters}

[35] The stress drop during the Chi-Chi earthquake ranges between 6.5 and $30 \mathrm{MPa}$ [Huang et al., 2001]. Considering that the zone of afterslip must have experienced a comparable coseismic (static) Coulomb stress increase, we may consider $\triangle \mathrm{CFF} \simeq 10 \mathrm{MPa}$. Using equation (A18) leads to

$$
a \bar{\sigma}=\frac{\Delta \mathrm{CFF}}{\log (d)} .
$$

Given that $d=640$, we infer $a \bar{\sigma} \simeq 1.5 \mathrm{MPa}$.

[36] An alternative way to estimate $a \bar{\sigma}$ is to use equation (16). The stressing rate $\dot{\tau}$ is roughly given by

$$
\dot{\tau}=\frac{\Delta \mathrm{CFF}}{T_{\text {inter }}},
$$

where $T_{\text {inter }}$ is the average time interval between two earthquakes similar to the 1999 Chi-Chi event. Using equation (16) together with equation (54) leads to

$$
a \bar{\sigma}=\frac{t_{r}}{T_{\text {inter }}} \Delta \mathrm{CFF} .
$$

Using $t_{r}=8.5$ years and $T_{\text {inter }} \simeq 150-250$ years [Dominguez et al., 2003], we found using equation (55) that $a \bar{\sigma} \simeq 0.34-$ $0.57 \mathrm{MPa}$. Therefore the estimate of $a \bar{\sigma}$ using equation (53) or (55) leads to the same order of magnitude, namely, $a \bar{\sigma} \simeq 0.34-1.5 \mathrm{MPa}$. Note also that the combination of equations (53) and (55) predicts that

$$
\log (d)=\frac{\Delta \mathrm{CFF}}{a \bar{\sigma}}=\frac{T_{\text {inter }}}{t_{r}}
$$

this last relation being only approximately verified in the case of the Chi-Chi earthquake since $\log (d)=\log (640) \simeq$ 6.5, while $T_{\text {inter }} / t_{r}$ ranges from 17.6 to 29.4.

[37] Given the fact that most of the aftershocks occurred at a depth of about $10 \mathrm{~km}(\mathrm{H}$. Kao, unpublished manuscript, 2002) and assuming that the mean normal stress $\bar{\sigma}$ may vary from the hydrostatic to the lithostatic pressure, we found that the mean normal stress is of the order of $\bar{\sigma}=$ 150-260 MPa. Assuming that $a \bar{\sigma} \simeq 0.34-1.5 \mathrm{MPa}$ leads to $a=\partial \mu / \partial \log (V) \simeq 1.310^{-3}-10^{-2}, \mu$ being the coefficient of friction of the BCFZ. This value makes sense in view of the sensitivity of friction to velocity changes estimated from laboratory experiments which fall in the range $a=510^{-3}-1.510^{-2}$ [Dieterich, 1994; Dieterich and Kilgore, 1996].

\section{Limitations of the Model}

[38] Our model is based on some strong hypothesis that might need to be discussed. First of all, the model is 1-D and therefore assumes that the fault has homogeneous properties. Even though it is well known that the stress field acting on the fault varies spatially (see, for instance, Bouchon et al. [1998] for the Landers earthquake), springslider models have been successful in describing the general behavior of 2-D fault models with spatially variable properties [Dieterich, 1992; Perfettini et al., 2003a, 2003b]. In addition, the assumption of a homogeneous fault is probably reasonable for a creeping fault which has a natural tendency to slide as a whole at constant velocity, in spite of spatial heterogeneities.

[39] Another limitation of the model is that it does not take into account the viscous relaxation of the deep crust or upper mantle. This should be true for moderate earthquakes which may not transfer high stress below the seismogenic zone but may be violated for very large earthquake such as the 1960, $M_{w}=9.5$, Chile earthquake [Khazaradze et al., 2002]. However, viscous relaxation occurs probably in a characteristic time much larger than the value of about 10 years inferred for $t_{r}$ (see discussion in section 5.2). If the viscosity of the deep crust is of the order of $10^{18} \mathrm{~Pa} \mathrm{~s}$, as deduced from case examples of viscoelastic response to lake level changes [Bills and May, 1987], the viscous relaxation time is of the order of a few thousand years.

[40] Another limiting assumption that we have made when modeling the Chi-Chi earthquake is that the contribution of aftershocks to seismicity rate changes is negligible. In case of aftershocks with significant coseismic deformation, the formalism we present could be modified to include these secondary sources of geodetic displacements and stress transfer. The model would then probably become too complex to help capture the real physics behind the observations.

\section{Conclusion}

[41] We contend that rate-strengthening brittle deformation might explain some aspect of fault behavior, in particular during postseismic relaxation. This mechanism might be dominant down dip of the seismogenic portion of a fault zone and might give rise to afterslip driving stress variation and hence coeval seismicity rate changes in the medium 
around. This physical rationale is shown here to be a viable hypothesis in the particular case of a dip-slip setting, but we believe it may apply more generally. A major limiting assumption of the analytical model presented here is that the postseismic response is assumed to be governed only by brittle creep at midcrustal depths. This is obviously not true since, in a number of case examples, it has been shown that postseismic relaxation does involve viscous flow at greater depth. However, we contend that brittle creep is a mechanism that must operate concurrently with other postseismic processes involving viscous deformation of the lithosphere but also fluid flow redistribution within the upper crust [Nur and Booker, 1972; Peltzer et al., 1998]. Future models of postseismic deformation should account for brittle creep because those based only on viscous deformation are probably biased toward a too small viscosity if forced to fit the early period of relaxation which is probably dominated by brittle creep. It should also be noticed that we have restricted the analysis to the case where brittle creep is only rate-dependent. If the fault zone is undergoing brittle creep static fatigue or instabilities inherent to rate-and-state friction laws [Rice and $G u, 1983$ ], it might also be at the origin of transient crustal deformation other than related to postseismic relaxation. With the development of geodetic monitoring, it has indeed become clear that major fault zones can produce a rich variety of transient deformation that radiate very little or no seismic waves. There are, for example, a number of observations of deep or shallow creep events following major earthquakes [e.g., Schaff et al., 1998; Hirose et al., 1999; Hutton et al., 2001; Fialko et al., 2002; Melbourne et al., 2002; Owen et al., 2002], but some slow events seem to have developed spontaneously [Sacks et al., 1981; Linde et al., 1996; Lowry et al., 2001; Dragert et al., 2001; Miller et al., 2002] and, in some cases, may have preceded and triggered large earthquakes [Katsumata et al., 2002]. In several cases the geodetic data show that afterslip occurred down dip of the locked fault portion, so probably in the BCFZ [Dragert et al., 2001; Hutton et al., 2001; Katsumata et al., 2002; Owen et al., 2002].

\section{Appendix A: Generalization to Any Type of Perturbations}

[42] The analytical derivation presented in section 3 cannot be applied to normal stress perturbations because the separation between the variables time displacement can no longer be carried on. We present here an approximation that applies to any type of stress perturbations. This approximation is based on earlier studies that considered 2-D faults governed by rate-and-state friction with depth variable frictional properties, to address the problem of static and dynamic triggering [Perfettini et al., 2003a, 2003b]. For most of the perturbations they have considered (stress steps, pulses, and wave packets) combining shear and normal stress variations, the Coulomb stress defined as

$$
\Delta \operatorname{CFF}(t)=\Delta \tau(t)-\mu_{*} \Delta \sigma(t),
$$

where $\mu_{*}$ is given in equation (7) and $\Delta \tau(t)(\Delta \sigma(t))$, the perturbation in the shear (normal) stress, is a good proxy to the effect of those perturbations.
[43] In the case of a variable effective normal stress with time, the strength of the fault $\tau_{f}$ is given by

$$
\tau_{f}(V, t)=\sigma(t) \mu(V) .
$$

The effective normal stress may indeed vary in particular due fluid pressure changes associated with compaction or dilatancy [Sleep, 1995; Marone, 1998]. As a first-order approximation we may write

$$
\sigma(t)=\bar{\sigma}+\dot{\sigma} t+\Delta \sigma(t)
$$

In the main text, $\dot{\sigma}=0$. We also assume that the normal stress variations during the seismic cycle of duration $T_{\text {inter }}$ are negligible compared to the total mean stress $\bar{\sigma}$, i.e., $|\Delta \sigma(t)| \ll \bar{\sigma}$ and $\left|\dot{\sigma} T_{\text {inter }}\right| \ll \bar{\sigma}$, those assumptions being reasonable at seismogenic depths. The coefficient of friction $\mu$ is given by

$$
\mu(V)=\mu_{*}^{\prime}+a \log (V)
$$

and we assume that it has no dependence on normal stress variations, the effect of the latter being mostly due to the proportionality between the strength $\tau_{f}$ and the normal stress. Such a hypothesis has to be made in order to still assume that the material is only rate-dependent. Considering the discussion above, equation (12) becomes, in the case of normal stress variations,

$$
\bar{\sigma} \mu(V)+\mu_{*} \Delta \sigma(t)+\mu_{*} \dot{\sigma} t \simeq \tau_{i}+k\left(V_{0} t-\delta\right)+\Delta \tau(t),
$$

or, equivalently,

$$
\bar{\sigma} \mu(V) \simeq \tau_{i}+\left(k V_{0}-\mu_{*} \dot{\sigma}\right) t-k \delta+\Delta \operatorname{CFF}(t),
$$

where $\triangle \mathrm{CFF}(t)$ is defined in equation (A1). We see that equation (A6) is equivalent to (12) when the perturbation in shear stress $\Delta \tau(t)$ is replaced by the Coulomb stress change $\Delta \mathrm{CFF}(t)$ and the stressing rate $\dot{\tau}=k V_{0}$ is replaced by the generalized stressing rate

$$
\dot{\tau}^{G}=\dot{\tau}-\mu * \dot{\sigma},
$$

which takes into account the shear and compaction of the fault zone. One can equivalently replace the loading velocity $V_{0}$ by a generalized loading velocity $V_{0}^{G}$ defined as

$$
V_{0}^{G}=\frac{\dot{\tau}-\mu_{*} \dot{\sigma}}{\dot{\tau}} V_{0}
$$

Note that the long-term sliding velocity $V_{0}^{G}$ is equal to the loading shear velocity $V_{0}$ only in the absence of compaction $(\dot{\sigma}=0)$.

[44] Therefore, in equations (18) and (20) we can replace the term $\Delta \tau(t)$ by $\Delta \mathrm{CFF}(t)$, the effective normal stress $\sigma$ by the normal stress $\bar{\sigma}$ acting on the fault when no perturbations in normal stress are considered, and the characteristic time $t_{r}$ by the generalized relaxation time $t_{r}^{G}$ defined as

$$
t_{r}^{G}=\frac{a \bar{\sigma}}{\dot{\tau}^{G}}=\frac{a \bar{\sigma}}{k V_{0}^{G}}
$$


Making those substitutions, the function $F(t)$ becomes

$$
F^{G}(t)=\int_{0}^{t} \exp \left[\frac{t^{\prime}}{t_{r}^{G}}+\frac{\Delta \mathrm{CFF}\left(t^{\prime}\right)}{a \bar{\sigma}}\right] d t^{\prime}
$$

where the index $G$ means "generalized." It is important to note that

$$
F^{G}(0)=0
$$

It is useful to introduce the generalize parameter $c^{G}$

$$
c^{G}=\frac{k}{a \bar{\sigma}},
$$

and to note that the following relation between the generalized parameters holds

$$
\frac{1}{c^{G} t_{r}^{G}}=V_{0}^{G}
$$

The generalized slip function $\delta^{G}(t)$ is given by

$$
\delta^{G}(t)=\delta_{i}+\frac{1}{c^{G}} \log \left[1+c^{G} V_{i} F^{G}(t)\right]
$$

while the generalized sliding velocity can be estimated using

$$
V^{G}(t)=V_{i} \frac{\exp \left[\left(t / t_{r}^{G}\right)+(\Delta \mathrm{CFF}(t) a \bar{\sigma})\right]}{1+c^{G} V_{i} F^{G}(t)} .
$$

The stress field generated by an earthquake may be expressed as

$$
\Delta \mathrm{CFF}(t)=\Delta \mathrm{CFF}^{d}(t)+\Delta \mathrm{CFF}^{s} H(t-\Delta t),
$$

where $\Delta \mathrm{CFF}^{d}(t)$ is the dynamic Coulomb stress field existing only for $t<\Delta t$ and $\Delta \mathrm{CFF}^{s} H(t-\Delta t)$ is the static Coulomb stress field active only when $t>\Delta t$. For such a stress field the function $F^{G}(t)$ can be written using $\Delta \operatorname{CFF}^{d}(t)=0$ for $t>\Delta t$

$$
F^{G}(t)=F^{G}(\Delta t)+t_{r}^{G} d^{G}\left[\exp \left(t / t_{r}^{G}\right)-\exp \left(\Delta t / t_{r}^{G}\right)\right]
$$

where we have introduced the generalized parameter $d^{G}$

$$
d^{G}=\exp \left(\Delta \mathrm{CFF}^{s} / a \bar{\sigma}\right) .
$$

It follows that

$$
\lim _{t \rightarrow \infty} F^{G}(t)=t_{r}^{G} d^{G} \exp \left(t / t_{r}^{G}\right)
$$

Using equation (A19), we find that

$$
\lim _{t \rightarrow \infty} \delta^{G}(t)=V_{0}^{G} t+\frac{\Delta \mathrm{CFF}^{s}}{k}+\frac{1}{c^{G}} \log \left(V_{i} / V_{0}^{G}\right),
$$

and

$$
\lim _{t \rightarrow \infty} V^{G}(t)=\frac{1}{c^{G} t_{r}^{G}}=V_{0}^{G}
$$

with the use of equation (A13). For an initial sliding velocity equal to the generalized loading velocity, i.e., $V_{i}=$ $V_{0}^{G}$, the long-term response of the slip function is equal to the slip in absence of perturbation (term $\delta_{0}+V_{0}^{G} t$ ) incremented by the slip due to the Coulomb stress step (term $\Delta \mathrm{CFF}^{s} / k$ ) for a pure elastic system with no "viscous" response (by viscous, we mean the positive $\log (V)$ dependence in the strength of the material). Equations (A20) and (A21) show that a creeping material will end up sliding at the loading velocity $V_{0}^{G}$ and that whatever the stress perturbations are.

[45] Acknowledgments. Comments by Chris Marone, Nadia Lapusta, Hiro Kanamori, the Associate Editor, and an anonymous reviewer have greatly helped to improve this article. We thank Anne Loevenbruck and Rodolphe Cattin for discussion about the Chi-Chi earthquake, Jean Schmittbuhl for discussion about fault mechanics, and Christian Mariotti for discussion about brittle creep rheology.

\section{References}

Baumberger, T., C. Caroli, B. Perrin, and O. Ronsin (1995), Nonlinear analysis of the stick-slip bifurcation in the creep-controlled regime of dry friction, Phys. Rev. E, 51, 4005-4010.

Baumberger, T., P. Berthoud, and C. Caroli (1999), Physical analysis of the state- and rate-dependent friction law. II. Dynamic friction, Phys. Rev. B, 60, 3928-3939.

Bills, B. G., and G. M. May (1987), Lake Bonneville: Constraints on lithospheric thickness and upper mantle viscosity from isostatic warping of Bonneville, Provo, and Gilbert stage shorelines, J. Geophys. Res., 92, $11,493-11,508$

Blanpied, M. L., D. A. Lockner, and J. D. Byerlee (1991), Fault stability inferred from granite sliding experiments at hydrothermal conditions, Geophys. Res. Lett., 18, 609-612.

Blanpied, M. L., D. A. Lockner, and J. D. Byerlee (1995), Frictional slip of granite at hydrothermal conditions, J. Geophys. Res., 100, 13,04513,064 .

Bouchon, M., M. Campillo, and F. Cotton (1998), Stress field associated with the rupture of the 1992 Landers, California, earthquake and its implications concerning the fault strength at the onset of the earthquake, J. Geophys. Res., 103, 21,091-21,097.

Burgmann, R., P. Segall, M. Lisowski, and J. Svarc (1997), Postseismic strain following the 1989 Loma Prieta earthquake from GPS and leveling measurements, J. Geophys. Res., 102, 4933-4955.

Cattin, R., and J. Avouac (2000), Modeling of mountain building and the seismic cycle in the Himalaya of Nepal, J. Geophys. Res., 105, 13,38913,407 .

Chen, Y.-G., W.-S. Chen, J.-C. Lee, Y.-H. Lee, C.-T. Lee, H.-C. Chang, and C.-H. Lo (2001), Surface rupture of 1999 Chi-Chi earthquake yields insights on active tectonics of central Taiwan, Bull. Seismol. Soc. Am., 91, 977-985.

Chester, F. M. (1995), A rheologic model for wet crust applied to strike-slip faults, J. Geophys. Res., 100, 13,033-13,044.

Cohen, S. C. (2000), Viscoelastic postseismic rebound from strike-slip earthquakes in regions of oblique plate convergence, Bull. Seismol. Soc. Am., 90, 1318-1322.

Deng, J., K. Hudnut, M. Gurnis, and E. Hauksson (1999), Stress loading from viscous flow in the lower crust and triggering of aftershocks following the 1994 Northridge, California, earthquake, Geophys. Res. Lett., 26, $3209-3212$.

Dieterich, J. H. (1979), Modeling of rock friction, 1, Experimental results and constitutive equations, J. Geophys. Res., 84, 2161-2168. 
Dieterich, J. H. (1992), Earthquake nucleation on faults with rate- and statedependent strength, Tectonophysics, 211, 115-134.

Dieterich, J. H. (1994), A constitutive law for rate of earthquake production and its application to earthquake clustering, J. Geophys. Res., 99, $2601-$ 2618.

Dieterich, J. H., and B. D. Kilgore (1994), Imaging surface contacts: power law ontact distribution and contact stresses in quartz, calcite, glass and acrylic plastic, Tectonophysics, 256, 219-239.

Dieterich, J. H., and B. Kilgore (1996), Implications of fault constitutive properties for earthquake prediction, Proc. Natl. Acad. Sci. USA., 93, 3787-3794

Dominguez, S., J.-P. Avouac, and R. Michel (2003), Horizontal coseismic deformation of the 1999 Chi-Chi earthquake measured from SPOT satellite images: Implications for the seismic cycle along the western foothills of central Taiwan, J. Geophys. Res., 108(B2), 2083, doi:10.1029/ 2001JB000951.

Dragert, H., K. Wang, and T. S. James (2001), A silent slip event on the deeper Cascadia subduction interface, Science, 292, 1525-1528.

Fialko, Y., D. Sandwell, D. Agnew, M. Simons, P. Shearer, and B. Minster (2002), Deformation on nearby faults induced by the 1999 Hector Mine earthquake, Science, 297, 1858-1862.

Fish, A. M. (1984), Thermodynamical model of creep at constant stress and constant strain rate, Cold Reg. Sci. Technol., 45, 143-161.

Frye, K. M., and C. Marone (2002), Effect of humidity on granular friction at room temperature, J. Geophys. Res., 107(B11), 2309, doi:10.1029/ 2001JB000654

Hearn, E. H., R. Burgmann, and R. E. Reilinger (2002), Dynamic of Izmit earthquake postseismic deformation and loading of the Duzce earthquake hypocenter, Bull. Seismol. Soc. Am., 92, 172-193.

Hirose, H., K. Hirahara, F. Kimata, N. Fujii, and S. Miyazaki (1999), A slow thrust slip event following the two 1996 Hyuganada earthquakes beneath the Bungo Channel, southwest Japan, Geophys. Res. Lett., 21, 3237-3240.

Hsu, Y.-J., N. Bechor, P. Segall, S.-B. Yu, L.-C. Kuo, and K.-F. Ma (2002), Rapid afterslip following the 1999 Chi-Chi, Taiwan earthquake, Geophys. Res. Lett., 29(16), 1754, doi:10.1029/2002GL014967.

Huang, W. G., J. H. Wang, B. S. Huang, K. C. Chen, T. M. Chang, R. D. Hwang, H. C. Chiu, and C. C. Tsai (2001), Estimates of source parameters for the 1999 Chi-Chi, Taiwan, earthquake based on Brune's source model, Bull. Seismol. Soc. Am., 91, 1190-1198.

Hutton, W., D. DeMets, O. Sánchez, G. Suárez, and J. Stock (2001), Slip kinematics and dynamics during and after the 1995 October $9 M_{w}=8.0$ Colima-Jalisco earthquake, Mexico, from GPS geodetic constraints, Geophys. J. Int., 146, 637-658.

Ji, C., T. Helmberger, T. Song, K. Ma, and D. Wald (2001), Slip distribution and tectonic implication of the 1999 Chi-Chi, Taiwan, earthquake, Geophys. Res. Lett., 28, 4379-4382.

Johnson, K. M., Y. J. Hsu, P. Segall, and S. B. Yu (2001), Fault geometry and slip distribution of the 1999 Chi-Chi, Taiwan earthquake imaged from inversion of GPS data, Geophys. Res. Lett., 28, 2285-2288.

Katsumata, K., M. Kasahara, S. Ozawa, and A. Ivashchenko (2002), A five years super-slow aseismic precursor model for the 1994 M8.3 HokkaidoToho-Oki lithospheric earthquake based on tide gauge data, Geophys. Res. Lett., 29(13), 1654, doi:10.1029/2002GL014982.

Khazaradze, G., K. Wang, J. Klotz, Y. Hu, and J. He (2002), Prolonged post-seismic deformation of the 1960 great Chile earthquake and implications for mantle rheology, Geophys. Res. Lett., 29(22), 2050, doi:10.1029/2002GL015986.

Lapusta, N., J. R. Rice, Y. Ben-Zion, and G. Zheng (2000), Elastodynamic analysis for slow tectonic loading with spontaneous rupture episodes on faults with rate- and state-dependent friction, J. Geophys. Res., 105, $23,765-23,789$

Lee, W. H. K. (2001), CD-ROM supplement of seismic data, Bull. Seismol. Soc., 91.

Linde, A., M. Gladwin, M. Johnson, R. Gwyther, and R. Bilham (1996), A slow earthquake sequence on the San Andreas fault, Nature, 383, 65-68.

Linker, M. F., and J. H. Dieterich (1992), Effects of variable normal stress on rock friction: Observations and constitutive equations, J. Geophys. Res., 97, 4923-4940.

Lockner, D. A. (1998), A generalized law for brittle deformation of Westerly granite, J. Geophys. Res., 103, 5107-5123.

Loevenbruck, A., R. Cattin, X. L. Pichon, M. L. Courty, and S. B. Yu (2001), Seismic cycle in Taiwan derived from GPS measurements, C. R Acad. Sci., Ser. IIa, 333, 57-64.

Lowry, A. R., K. M. Larson, V. Kostoglodov, and R. Bilham (2001), Transient fault slip in Guerrero, southern Mexico, Geophys. Res. Lett., 28, 3753-3756

Ma, K. F., J. Mori, S. J. Lee, and S. B. Yu (2001), Spatial and temporal slip distribution of the Chi-Chi, Taiwan, earthquake from strong motion, teleseismic and GPS data, Bull. Seismol. Soc. Am., 91, 1069-1087.
Main, I. G. (2000), A damage mechanics model for power-law creep and earthquake aftershock and foreshock sequences, Geophys. J. Int., 142, $151-161$.

Marone, C. (1998), Laboratory-derived friction laws and their application to seismic faulting, Annu. Rev. Earth Planet. Sci., 26, 643-696.

Marone, C. J., and C. H. Scholz (1988), The depth of seismic faulting and the upper transition from stable to unstable slip regimes, Geophys. Res. Lett., 15, 621-624.

Marone, C. J., C. B. Raleigh, and C. H. Scholz (1990), Frictional behavior and constitutive modeling of simulated fault gouge, J. Geophys. Res., 95, $7007-7025$

Marone, C. J., C. H. Scholz, and R. Bilham (1991), On the mechanics of earthquake afterslip, J. Geophys. Res., 96, 8441-8452.

Melbourne, T. I., F. H. Webb, J. M. Stock, and C. Reigber (2002), Rapid postseismic transients in subduction zones from continuous GPS, J. Geophys. Res., 107(B10), 2241, doi:10.1029/2001JB000555.

Miller, M. M., T. Melbourne, D. J. Johnson, and W. Q. Sumner (2002), Periodic slow earthquakes from the Cascadia subduction zone, Science, 295,2423

Mitchell, J. K. (1976), Fundamentals of Soil Behavior, 422 pp., John Wiley, Hoboken, N. J.

Nur, A., and J. Booker (1972), Aftershocks caused by pore fluid-flow, Science, 175,885 .

Owen, S., G. Anderson, D. C. Agnew, H. Johnson, K. Hurst, R. Reilinger, Z.-K. Shen, J. Svarc, and T. Baker (2002), Early postseismic deformation from the 16 October $1999 M_{w} 7.1$ Hector Mine, California, earthquake as measured by survey-mode GPS, Bull. Seismol. Soc. Am., 92, 1423-1432.

Parsons, T. (2002), Global Omori law decay of triggered earthquakes: Large aftershocks outside the classical aftershock zone, J. Geophys. Res., 107(B9), 2199, doi:10.1029/2001JB000646.

Peltzer, G., P. Rozen, F. Rogez, and K. Hudnut (1998), Poroelastic rebound along the Landers 1992 earthquake surface rupture, J. Geophys. Res., 103, 30,131-30,145.

Perfettini, H., J. Schmittbuhl, and A. Cochard (2003a), Shear and normal load perturbations on a two-dimensional continuous fault: 1 . Static triggering, J. Geophys. Res., 108(B9), 2408, doi:10.1029/2002JB001804.

Perfettini, H., J. Schmittbuhl, and A. Cochard (2003b), Shear and normal load perturbations on a two-dimensional continuous fault: 2. Dynamic triggering, J. Geophys. Res., 108(B9), 2409, doi:10.1029/2002JB001805.

Pollitz, F. F. (2001), Viscoelastic shear zone model of a strike-slip earthquake cycle, J. Geophys. Res., 106, 26,541-26,560.

Pollitz, F. F., R. Burgmann, and P. Segall (1998), Joint estimation of afterslip rate and postseismic relaxation following the 1989 Loma Prieta earthquake, J. Geophys. Res., 103, 26,975-26,992.

Pollitz, F. F., G. Peltzer, and R. Burgmann (2000), Mobility of continental mantle: Evidence from postseismic geodetic observations following the 1992 Landers earthquake, J. Geophys. Res., 105, 8035-8054.

Rice, J. R. (1993), Spatio-temporal complexity of slip on a fault, J. Geophys. Res., 98, 9885-9907.

Rice, J. R., and J. Gu (1983), Earthquake aftereffects and triggered seismic phenomena, Pure Appl. Geophys., 121, 187-219.

Rice, J. R., and A. L. Ruina (1983), Stability of steady frictional slipping, J. Appl. Mech., 50, 343-349.

Ruina, A. L. (1983), Slip instability and state variable friction laws, J. Geophys. Res., 88, 10,359-10,370.

Sacks, I. S., A. T. Linde, J. A. Snoke, and S. Suyehiro (1981), A slow earthquake sequence following the Izu-Oshima earthquake of 1978, in Earthquake Prediction: An International Review, Maurice Ewing Ser., vol. 4, edited by D. W. Simpson and G. P. Richards, pp. 617-628, AGU, Washington, D. C

Savage, J. C., and J. L. Svarc (1997), Postseismic deformation associated with the $1992 M_{w}=7.3$ Landers earthquake, southern California, J. Geophys. Res., 102, 7565-7577.

Schaff, D. P., G. C. Beroza, and B. E. Shaw (1998), Postseismic response of repeating aftershocks, Geophys. Res. Lett., 25, 4549-4552.

Scholz, C. H. (1990), The Mechanics of Earthquakes and Faulting, Cambridge Univ. Press, New York.

Segall, P., and J. R. Rice (1995), Dilatancy, compaction, and slip instability of a fluid infiltrated fault, J. Geophys. Res., 100, 22,155-22,171.

Segall, P., R. Brgmann, and M. Matthews (2000), Time-dependent triggered afterslip following the 1989 Loma Prieta earthquake, J. Geophys. Res., $105,5615-5634$

Singh, A., and J. Mitchell (1968), General stress-strain-time function for soils, J. Soil. Mech. Found. Div. Am. Soc. Civ. Eng., 99, 21-46.

Sleep, N. H. (1995), Ductile creep, compaction, and rate and state dependent friction within major fault zones, J. Geophys. Res., 100, 13,06513,080 .

Sleep, N. H. (1997), Application of a unified rate and state friction theory to the mechanics of fault zone with strain localization, J. Geophys. Res., $102,2875-2895$ 
Trepmann, C. A., and B. Stockhert (2002), Cataclastic deformation of garnet: A record of synseismic loading and postseismic creep, J. Struct. Geol., 24, 1845-1856.

Tse, S. T., and J. R. Rice (1986), Crustal earthquake instability in relation to the depth variation of frictional slip properties, J. Geophys. Res., 91, $9452-9472$

Yu, S. B., H. Y. Chen, and L. C. Kuo (1997), Velocity field of GPS stations in the Taiwan area, Tectonophysics, 274, 41-59.

$\mathrm{Yu}, \mathrm{S} .-\mathrm{B} .$, et al. (2001), Preseismic deformation and coseismic displacements associated with the 1999 Chi-Chi, Taiwan earthquake, Bull. Seismol. Soc. Am., 91, 995-1012.
Zheng, G., R. Dmowska, and J. R. Rice (1996), Modeling earthquake cycles in the Shugamin subduction segment, Alaska, with seismic and geodetic constraints, J. Geophys. Res., 101, 8383-8392.

J.-P. Avouac, Geological and Planetary Sciences, California Institute of Technology, Mail Code 100-23, Pasadena, CA 91125, USA. (avouac@gps. caltech.edu)

H. Perfettini, Université Paul Sabatier, Institut de Recherche pour le Développement/Laboratoire des Mécanismes de Transferts en Géologie, 38 rue des 36 ponts, F-31400, Toulouse, France. (perfetti@lmtg.ups-tlse.fr) 